\title{
"A comunicação no lactente"
}

\author{
Maria Goretti Angarten *
}

RBEn/06

ANGARTEN, M. G. - A comunicaçăo no lactante. Rev. Bras. Enf.; DF, 33 : 190-193, 1980.

\section{I - INTRODUÇAO}

Sociólogos como Gerog Simmel voltaram sua atenção para possibilidades de pesquisas sociológicas no grupo mãefilho e sublinharam que é nesse ponto que se poderá encontrar o germe de todo o desenvolvimento ulterior das relações sociais.

O fato de que a primeira de todas as relações estabelecidas na vida do lactente deve ser uma relação com um companheiro humano é importante, pois todo desenvolvimento social ulterior se apoiará neste fato, tendo aqui o início de um desenvolvimento que finalmente conduzirá o homem a fim de que se torne um ser humano, o ser social; e no início espeficamente humano das interrelações sociais se coloca o desenvolvimento da expressão facial, seu uso semântico, que terminará finalmente com o desenvolvimento da palavra e da linguagem.

\section{II - ASPECTOS DO PROCESSO DE COMUNICAÇAO NO LACTENTE}

Cherry define comunicação de um modo geral como o estabelecimento de uma unidade social a partir de Indivíduos pelo uso de linguagem ou signos, e para Allen comunicação é a soma de todas as colsas que uma pessoa faz quando procura ser compreendida por outra.

Na comunicação verbal devem estar presentes seis fatores: 0 remetente, 0 destinatário, a mensagem, o contexto, o contato (canal) e o código. $O$ remetente envia uma mensagem ao destinatário construída com um código comum ao remetente e destinatário, referente a um contexto apreensível pelo destinatário e que seja verbal ou susceptível de verbalização. Há necessidade de um canal físico (contato) que capacite a ambos entrarem e permanecerem em comunicação. Podemos esquematizar da seguinte maneira o comunicação verbal:

- Enfermeira pediatra pelo Departamento de Enfermagem da Escola Paulista de Medicina.

Enfermeira Supervisora da Associação Hospital Oswaldo Cruz. 


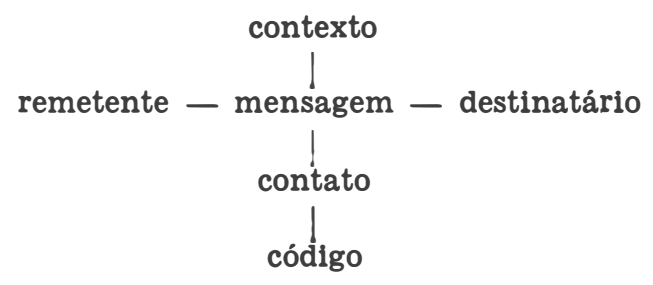

Toda mensagem tem um objetivo, por isso se diz que ela tem várias funções e significados. Para que a mensagem se exteriorize e seja entendida pelo destinatário é preciso que ela tenha um significado e um significante, isto é, um conceito vinculado a uma imagem psíquica cujo conjunto designamos signo. Para Collin signo é a transmissão ou construção mental por via da qual uma pessoa influencia o comportamento ou estudo de outra pessoa numa situação de comunicação.

O recém-nascido (RN) é um ser imaturo tanto física quanto psiquicamente e vive suas primeiras experiências extra útero que se apresentam de uma maneira nova e diversa. O choro é a única expressão do RN levada em consideração pelo adulto como tentativa de comunicação. Em lingüística o choro do RN é considerado um signo natural ou indice, pois nesta condição o signo é transmitido sem intenção de comunicar.

O pensamento não nasce assim que a criança nasce (Freud), mas recebe estímulos a partir de que nasce, fazendo com que se interiorizem no aparelho psíquico e se organizem em sistemas através do princípio da associação. Toda a percepção no RN processa-se em função do sistema interoreceptor, as respostas manifestadas pelo RN são originadas em função da percepção de necessidade que lhe são comunicadas por este sistema. Pode-se observar as respostas de desprazer desde o nascimento. Freud fala do traumatismo do parto apenas como protótipo físiológico, sendo um estado extremamente transitório e que dura na maioria das vezes apenas alguns segundos no RN normal. Durante as primeiras horas e os primeiros dias de vida, o matiz do desprazer é o único que se pode observar. Um princípio enunciado por Freud consiste na tendência de reduzir as tensões, mostrando que a contrapartida não é o prazer, mas a quietude.

Assim, o RN ainda que tenha uma individualidade demonstrável, não tem uma organização da personalidade e sua interação com o ambiente é puramente fisiológica (Spitz). Hartman, designa um estado de organização primitiva do RN, pois está incapaz de distinguir um objeto do outro.

Para o RN o seu ambiente composto de um só indivíduo, a mãe ou substituto, não é percebido como uma entidade dele, mas tão somente como uma parte do conjunto de suas necessidades e de sua satisfação.

Durante os três primeiros meses de vida, as experiências do lactente se limitam, com efeito, ao afeto, o "sensorium", a discriminação e o aparelho perceptivo não estão ainda desenvolvidos sob o ponto de vista psicológico e mesmo sob o ponto de vista físico. Será então a atitude afetiva da mãe, que servirá de orientação para o lactente.

Experiências de vários autores demonstraram que o seu mundo exterior é incluído através da percepção com um limiar de percepção extremamente elevado, podendo-se dizer que no período de mais ou menos três meses, o mundo exterior é inexistente para ele. No entanto ultrapassado o limiar de percepção, o RN sai da quietude em que está mergulhado com desprazer, manifestado por um índice que é um signo natural (Lopes), aqui especificamente representado pelo choro. Vale a pena lembrar que nesse período o RN não tem intenção de comunicar.

As respostas do RN são na melhor das hipóteses de natureza de um reflexo 
ANGarten, M. G. - A comunicação no lactante. Rev. Bras. Enf.; DF, 33 : 190-193, 1980.

condicionado (Spitz); evidentemente muitos dias deverão passar antes que uma resposta específica, ainda que tão primitiva quanto um reflexo condicionado, possa desenvolver-se. Porquanto se faz necessário que algum tempo tenha se passado, provavelmente três meses (Penna) para que um condicionamento possa ser realizado.

Por outro lado Leboyer defende que na instalação da respiração já se implanta o primeiro reflexo condicionado, um reflexo no qual respiração e angústia estão extremamente associados. Porém preferimos as idéias de Spitz e Penna quanto à época dos primeiros reflexos condicionados, pois Leboyer nas fontes consultadas é o único que considera a instalação do reflexo condicionado desde o nascimento, fato não amplamente aceito que merece novas investigações.

Filmes de Spitz e colaboradores demontraram de uma maneira surpreendente como o seio da mãe, suas mãos, seus dedos oferecem à criança todos os estímulos tácteis para a aprendizagem da preensão e da orientação táctil; como seu corpo e seus movimentos oferecem à criança as experiências necessárias para o seu equilíbrio e a sua voz oferece à criança os estímulos auditivos necessários para a formação da linguagem. Uma série de investigações sistemáticas e pormenorizadas demonstraram recentemente até que ponto é importante o meio ambiente para o desenvolvimento da linguagem. A influência do meio principia extraordinariamente cedo e seus efeitos são duradouros. O efeito estimulante de um meio familiar normal não pode deixar de ser realçado (Sandström).

No terceiro mês de vida, devido ao amadurecimento somático e desenvolvimento psíquico, sua resposta à experiências quando defrontados com o rosto humano, será sempre um sorriso, desde que este rosto seja apresentado de frente e de maneira que os dois olhos este- jam bem visíveis, e ainda é necessário que $o$ rosto esteja em movimento. Se o lactente estiver sendo alimentado artificialmente, freqüentemente nota-se modificação neste comportamento. Eles tentarão agarrar a mamadeira, porém não sorrirão. Entretanto, por esta época, todos os lactentes responderão com um sorriso ao sorriso do adulto, descrito em trabalho de Spitz "La réponse por la sourrire". O adulto poderá ser não obrigatoriamente a mãe, mas qualquer um pode provocar o sorriso se preencher as condições prescritas pela "Gestalt" privilegiada que consiste no conjunto formado pela fronte, olhos, nariz e o todo em movimento.

As ações bem sucedidas, provocam prazer no lactente. Ele repete e aprende a manejá-las. A mãe dirige o lactente para suas preferências e se sua atitude é terna, toda atividade dará prazer ao lactente facilitando a multiplicidade de ações devido as atitudes da mãe, quer sejam elas conscientes ou inconscientes (Freud).

O lactente fica isolado até certo ponto em seu ambiente das demais pessoas, só à mãe ele está unido por laços extraordinariamente poderosos. São liames afetivos unindo a dupla mãe e filho cem vezes mais poderosos do que o amor que já foi denominado de um egoísmo a dois (Spitz). A simples presença, a existência da mãe forma um estímulo para as respostas do lactente.

A desigualdade dos participantes no processo de comunicação é que caracteriza a comunicação entre lactente e mãe.

A partir do terceiro mês de vida o processo de comunicação estabelecido entre lactente e mãe se dá pela intenção de comunicar através da mensagem que tem uma função eminentemente fática, devido ao amadurecimento psíquico suficiente para iniciar o processo de comunicação e estabelecimento do reflexo condicionado. Este tipo de mensagem tem finalidade de estabelecer o contato 
entre dois interlocutores em potencial, criar solidariedade, chamar a atenção, sondar o ânimo.

A evolução do processo de comunicação no lactente val sofrer transformações até atingir a comunicação verbal do adulto. Na fase pré-verbal sempre será importante a utilização de todos os órgãos dos sentidos como canal de comunicação.

\section{III - CONCLUSOES E SUGESTOES}

As diferenças individuais entre as mães, são necessariamente infinitas. A forma dos sentimentos, das respostas, (ào comportamento afetivo de cada mãe é também vasto. Por sua vez, esta gama que cada mãe possuí será influenciada pelas atitudes e expressões de seu filho, formando um processo circular.
Toda mãe deverá ser orientada desde o pré-natal sobre cuidados com o lactente para adequada estimulação sensorial visando um relacionamento mãe-filho satisfatório, propiciando um desenvolvimento psicológico sadí. Esta estimulação será global, incluindo necessariamente a expressão verbal do adulto. $O$ início deve ser precoce, devendo a mãe ser orientada para escolher a maternidade com sistema alojamento conjunto, onde estará sob a supervisão de profissional especializado que ajudará o início da prática da estimulação sensorial do lactente.

O pessoal do berçário convencional e do sistema alojamento conjunto deverá ser orientado para oferecer e orientar a adequada estimulação sensorial do lactente, ajudando a promovê-la.

\section{BIBLIOGRAFIA}

BELUZZI, D. O Chors do RN. J. Ped. 37 $(3-4)$ : 81-83. 1972.

CHERRY, H. Distúrbios neuróticos da criança. Såo Paulo, Procieux, 1965. 633 p.

HARUNARI, L. O Sistema Alojamento Conjunto para $R N$ e mãe em maternidade ou em Unidade Obstétrica como contribuiçāo fara assistência integral ao $R N$. São Paulo, CESC e CEBRAE, 1977. 115 p. (Tese de Livre Docente e Doutoramento apresentada a Undversidade Federal do Rlo Grande do Sul).

JAKOBSON, R. Lingiiistica e Comunicação: Såo Paulo, Cultrix, 1975. 162 p.
LEBOYER, F. Nascer sorrindo. Rio de Janeiro, Brasiliense, 1975. 203 p.

LOPES, E. Fundamentos da lingüistica contemporânea. São Paulo, Cultrix, 1977. $347 \mathrm{p}$.

PENNA. H. Choro. In: ALCANTRA, P. et al. Pediatria Básica. 5." ed. Săo Paulo, Sarvier, 1975. Vol. 1. p. 212-15

SANDSTROM, C. I. A psicologia da infância $e$ da adolescência. 2. ${ }^{\text {a }}$ ed. Rio de Janeiro, Zaha,d 1966. 288 p.

SPITZ, R. A. Desenvolvimento emocional do recém-nascido. Río de Janelro, Ploneira, 1960. $159 \mathrm{p}$. 